\title{
Improvement of Bond Strength between Zirconia Framework and Veneering Porcelain
}

\author{
Yuhui Chen ${ }^{1}$, Chuhua Tang ${ }^{1 *}$, Shenggen Shi ${ }^{1 *}$, Wenjie $\mathrm{Si}^{2,3}$ and Xiao $\mathrm{Liu}^{3}$
}

${ }^{1}$ Diagnosis \& Treatment Center of Oral Diseases of the PLA, The 306th Hospital of the PLA, Beijing, China

${ }^{2}$ School of Materials Science and Engineering, Tsinghua University, Beijing, China

${ }^{3}$ Shenzhen Upcera Dental Technology Co., Ltd, Shenzhen, China

\begin{abstract}
A series of specimens with different surface morphology, pre-sintering process, and sintering temperature were designed for studying the improvement of bond strength between zirconia framework and veneering porcelain. Shear strength test, Scanning Electron Microscope (SEM), and Energy Dispersive Spectrometer (EDS) were adopted in the investigation. A remarkably enhance of average bond strength from $24.1 \mathrm{MPa}$ to $37.2 \mathrm{MPa}$ was obtained by performing humps on zirconia substrate. Moreover, a pre-sintering process for bonding porcelain was beneficial to the increasing of bond strength. Hence, during all-ceramic dental restoration fabrication, it is promising to perform surface treatment on zirconia and conduct pre-sintering procedure on bonding porcelain for the improvement of bond strength between zirconia framework and veneering porcelain.
\end{abstract}

Keywords: Zirconia restoration; Veneering porcelain; Bond strength

\section{Introduction}

Clinical statistics show that, the defect and absence of tooth is a common disease with a high morbidity of $24-53 \%$ in dental treatment. Thus, it is promising to develop dental restoration materials with favorable mechanical strength and excellent bio-safety [1-4]. In the past decades, metals and alloys have been widely used in dental restorations. However, with the increasing esthetic requirement from patients and the development of CAD/CAM (Computer Aided Design/Computer Aided Manufacturing) technique, various all-ceramic materials have been adopted in dental restoration for their aesthetical potential [5-7]. Among numerous dental ceramics, zirconia based materials possess most promising prospects due to their fascinating aesthetic performance, favorable biocompatibility, and superior mechanical property [8].

Commercially used dental zirconia usually contains 3-6 mol\% of Yttria as the stabilizer, since Yttria partially stabilized tetragonal zirconia polycrystalline (Y-TZP) showed better mechanical properties and fracture toughness compared to other dental ceramics [9]. The excellent mechanical strength of Y-TZP originated from the crystalline phase transformation from a tetragonal to a monoclinic structure. Due to unsatisfying translucency of Y-TZP, a bilayered structure consisting of a zirconia substrate and a brittle glass-ceramic veneering layer is frequently used to improve the aesthetical appearance of zirconia prosthesis.

In vitro investigations indicated that $\mathrm{Y}$-TZP holds flexural strength ranging from $900-1200 \mathrm{MPa}$ and fracture toughness of 5-10 MPa/m². However, as reported by Sailer et al. the failure incidence for zirconia ceramic restoration in 3 and 5 years turned out to be $13.0 \%$ and $15.2 \%$, respectively [10]. Short-term and mid-term clinical observations indicate that chipping and fragmentation of veneering porcelain were the most common reasons for the failure of all-ceramic restorations. To decreasing the risk of chipping, it is crucial to improve the bond strength between zirconia and veneering porcelain [11-13].

In this study, a series of specimens with zirconia substrate and veneering porcelain were prepared. Different surface morphology, presintering process, and sintering temperature were designed. The shear strength test indicated that, the striations made no obvious difference to bond strength, while humps on zirconia substrate could obviously enhanced the bond strength between zirconia substrate and veneering porcelain. Due to the element diffusion, which was confirmed by Energy Dispersive Spectrometer (EDS), the bond strength was increased by a pre-sintering process for bonding porcelain. Moreover, the sintering temperature of veneering porcelain was optimized to be $960^{\circ} \mathrm{C}$.

\section{Materials and Methods}

\section{Specimen preparation}

Partially-sintered Kavo zirconia blocks (Kavo Corp., Germany) with the same batch and the same after-sintered size of $11 \times 10 \times 5 \mathrm{~mm}$ were used in this study. The specimens were cut and milled by Kavo CAD/ CAM system (Kavo Corp., Germany). Afterwards, the specimens were ground by $120,200,400,600,800$, and 1000 grit $\mathrm{SiC}$ paper sequentially, and polished adopting $15 \mu \mathrm{m}$ diamond paste. They were sandblasted by alumina particles of $120 \mu \mathrm{m}$ at $0.15 \mathrm{MPa}$ for 20 seconds. Finally, the specimens were cleaned by ultrasonic cleaning for $10 \mathrm{~min}$, and dried by infrared drying light. The veneering process was performed using KISS veneering porcelain (Degudent Corp., Germany) on the fully sintered zirconia, and the sintering process was performed by Ney Centurion Q 50 porcelain furnace (Ney Dental Inc, American).

To investigate the effect of surface morphology on the bond strength, 40 specimens were divided into 4 groups (Group 1.1, Group 1.2, Group 1.3, and Group 1.4). Group 1.1 was designed with striations (width of striations: $8 \mu \mathrm{m}$, space between striations: $160 \mu \mathrm{m}$ ) vertical to

*Corresponding authors: Chuhua Tang, Diagnosis \& Treatment Center of Oral Diseases of the PLA, The 306th Hospital of the PLA, Beijing, China, Tel: 8613910687917; E-mail: tch306@126.com

Shenggen Shi, Diagnosis \& Treatment Center of Oral Diseases of the PLA The 306th Hospital of the PLA, Beijing, China, Tel: 8613661037718; E-mail: shishengen@sohu.com

Received November 26, 2015; Accepted December 23, 2015; Published December 31, 2015

Citation: Chen Y, Tang C, Shi S, Si W, Liu X (2015) Improvement of Bond Strength between Zirconia Framework and Veneering Porcelain. Dentistry 6: 352 doi:10.4172/2161-1122.1000352

Copyright: ( $) 2015$ Chen Y, et al. This is an open-access article distributed under the terms of the Creative Commons Attribution License, which permits unrestricted use, distribution, and reproduction in any medium, provided the original author and source are credited. 
the orientation of shear force. Group 1.2 was designed with striations (width of striations: $8 \mu \mathrm{m}$, space between striations: $160 \mu \mathrm{m}$ ) parallel to the orientation of shear force. Group 1.3 was designed with cylindrical humps (diameter: $2 \mathrm{~mm}$, height: $0.3 \mathrm{~mm}$ ). Group 1.4 with no surface treatment was adopted as control group. After surface treatments by scheduled procedure of CAD/CAM system, the specimens were coated with bonding porcelain, and sintered at $980^{\circ} \mathrm{C}$ for $1 \mathrm{~min}$, and then, the veneering layer was built in the size of $10 \times 5 \times 4 \mathrm{~mm}$ near the bonding porcelain, and sintered at $980^{\circ} \mathrm{C}$ for $1 \mathrm{~min}$.

To investigate the effect of pre-sintering process for bonding porcelain on the bond strength, 20 specimens were divided into 2 groups (Group 2.1 and Group 2.2). Both groups were cut, ground, polished, sandblasted and cleaned by the same way mentioned above. Group 2.1 was adopted as the control group. After cleaning and drying, specimens in Group 2.1 were pre-sintered at $1000^{\circ} \mathrm{C}$ for 15 min directly, while specimens in Group 2.2 were coated with bonding porcelain, and then pre-sintered at $1000^{\circ} \mathrm{C}$ for $15 \mathrm{~min}$. After cooling into room temperature, the specimens both in Group 2.1 and Group 2.2 were covered by veneering porcelain $(10 \times 5 \times 4 \mathrm{~mm})$ and sintered at $980^{\circ} \mathrm{C}$ for $1 \mathrm{~min}$.

To investigate the effect of sintering temperature on the bond strength, 110 specimens were divided into 11 groups (Group 3.1 to Group 3.11). After the general processing mentioned above, the specimens in 11 groups were coated with bonding porcelain, and presintered at $1000^{\circ} \mathrm{C}$ for $15 \mathrm{~min}$. After cooling into room temperature, the specimens from Group 3.1 to Group 3.11 were covered by veneering porcelain $(10 \times 5 \times 4 \mathrm{~mm})$ and sintered at the temperature of $900^{\circ} \mathrm{C}$, $910^{\circ} \mathrm{C}, 920^{\circ} \mathrm{C}, 930^{\circ} \mathrm{C}, 940^{\circ} \mathrm{C}, 950^{\circ} \mathrm{C}, 960^{\circ} \mathrm{C}, 970^{\circ} \mathrm{C}, 980^{\circ} \mathrm{C}, 990^{\circ} \mathrm{C}$ and $1000^{\circ} \mathrm{C}$, respectively, for $1 \mathrm{~min}$.

\section{Testing method}

The fracture surface appearance observation and energy spectrum analysis of specimen was carried out by JSM-6310F SEM.

To perform the shear strength test, the specimens were put into the fixture, and the fixture was laid on the plinth of the universal testing machine. The load was vertical to the bonding interface at the speed of $0.1 \mathrm{~mm} / \mathrm{min}$ referring to criterion of YY0716-2009. The maximum shear loads were taken notes when the samples were broken down. Shear strength was obtained by the formula of $\mathrm{P}=\mathrm{F} / \mathrm{S}$ (MPa), where $\mathrm{P}$ is the shear strength, $\mathrm{F}$ is the ultimate shear load, and $\mathrm{S}$ is the area of veneering porcelain.

SPSS 13.0 software was used for statistical analyses, and least significant difference (LSD) test between groups were performed to compare the shear strength of specimens in different groups. Pearson correlation was introduced in this study, and the $p>0.05$ indicating no significant difference between data, and there was no statistical significance, while the $\mathrm{p}<0.05$ indicating significant difference between data, and there was statistical significance.

\section{Results and Discussion}

\section{Effect of surface morphology on the bond strength}

Figure 1 shows the surface treatments of zirconia substrates in Group 1.1, 1.2, and 1.3. As shown in Table 1, the average values and standard deviations of shear strength for specimens in Group 1.1 to 1.4 were measured to be $27.9 \pm 4.53 \mathrm{MPa}, 27.5 \pm 4.79 \mathrm{MPa}, 37.2 \pm 7.03 \mathrm{MPa}$ and $24.1 \pm 2.64 \mathrm{MPa}$, respectively. The average shear strength of Group 1.3 was obviously higher than those of Groups 1.1, 1.2 and 1.4. The p-value between each two groups from 1.1 to 1.4 was shown in Table
2. Obviously, there is statistical significance of shear strength between Group 1.3 and Group 1.1, 1.2, and 1.4, respectively. It is safe to say that, the striations made no obvious difference to the bond strength, while humps in the surface of zirconia substrate remarkably enhanced the bond strength between zirconia substrate and veneering porcelain. Therefore, it is promising to design humps on zirconia substrate to reduce chipping of veneering porcelain.

Figure 2 showed the appearance of fracture surface after shear test. Residual veneering porcelains were found in the surface of zirconia frameworks, the residual veneering porcelain on zirconia framework in Group 3 was especially more.

\section{Effect of pre-sintering process on the bond strength}

The average values of shear strength for specimens in Group 2.1 and 2.2 were measured to be $24.78 \pm 3.60 \mathrm{MPa}$ and $43.12 \pm 4.50 \mathrm{MPa}$,
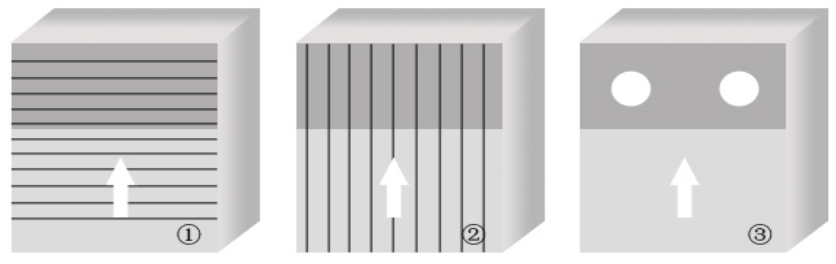

Figure 1: Surface morphology of zirconia bodies in Group 1, 2, and 3 after treatments.

\begin{tabular}{|c|c|c|c|c|}
\hline Group No. & $\begin{array}{c}\text { Maximum } \\
\text { (MPa) }\end{array}$ & $\begin{array}{c}\text { Minimum } \\
\text { (MPa) }\end{array}$ & $\begin{array}{c}\text { Average } \\
\text { (MPa) }\end{array}$ & $\begin{array}{c}\text { Standard } \\
\text { deviation }\end{array}$ \\
\hline 1.1 & 35 & 23 & 27.90 & 4.53 \\
\hline 1.2 & 36 & 23 & 27.50 & 4.79 \\
\hline 1.3 & 49 & 30 & 37.20 & 7.03 \\
\hline 1.4 & 28 & 21 & 24.10 & 2.64 \\
\hline \multicolumn{4}{|c|}{ Value of F } & $12.613^{*}$ \\
\hline
\end{tabular}

*: significant difference $(p<0.05)$

Table 1: The average values and standard deviations of shear strength for specimens in Groups 1.1 to 1.4 .

\begin{tabular}{|c|c|c|c|c|}
\hline Group No. & $\mathbf{1 . 1}$ & $\mathbf{1 . 2}$ & $\mathbf{1 . 3}$ & $\mathbf{1 . 4}$ \\
\hline 1.1 & - & 0.18 & 0.008 & 0.32 \\
\hline 1.2 & ns & - & 0.009 & 0.44 \\
\hline 1.3 & $* *$ & $* *$ & - & 0.42 \\
\hline 1.4 & ns & ns & $*$ & - \\
\hline
\end{tabular}

ns: no significant difference $(p>0.05)$; *: significant difference $(p<0.05)$; ${ }^{*}$ : very significant difference $(p<0.01)$.

Table 2: p-value between each two groups from Groups 1.1 to 1.4 .

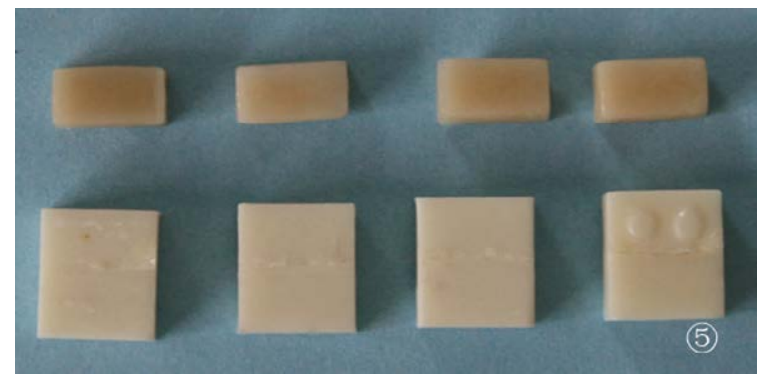

Figure 2: The appearance of fracture surface after shear test. 
Citation: Chen Y, Tang C, Shi S, Si W, Liu X (2015) Improvement of Bond Strength between Zirconia Framework and Veneering Porcelain. Dentistry 6: 352. doi:10.4172/2161-1122.1000352

Page 3 of 4

respectively. Besides, $\mathrm{p}<0.05$ indicates the statistical significance. Hence, the pre-sintering process of bonding porcelain at $1000^{\circ} \mathrm{C}$ for 15 min was beneficial in improving the bond strength between zirconia framework and veneering porcelain.

The Scanning Electron Microscope (SEM) photo for specimens in Group 2.1 and 2.2 were shown in Figure 3. After sintering, the zirconia layer and porcelain layer for specimens in Group 2.1 were compact and uniform, the sintered interface was smooth and clear, and no obvious pore has been detected. As for specimens in Group 2.2, the

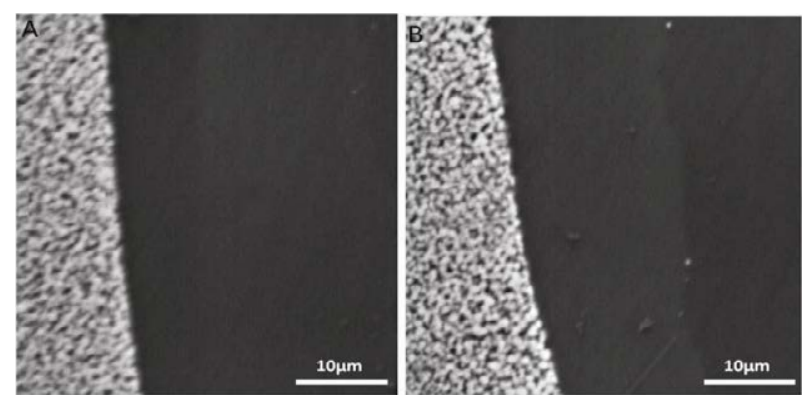

Figure 3: The SEM photos of bonding interface for specimens in Group 2.1 and 2.2 .
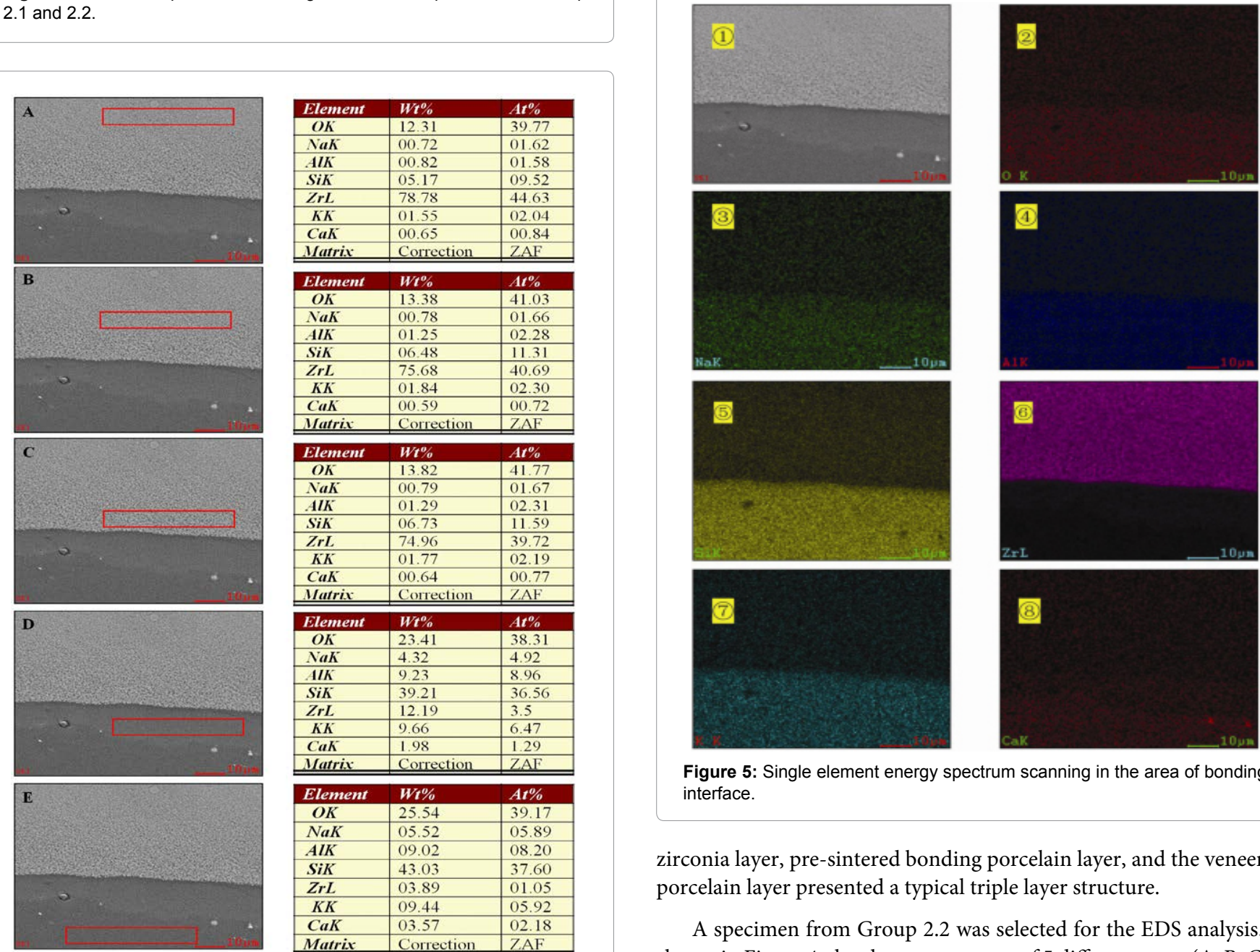

Table 4: Atom percentage of element content in different areas between the veneering porcelain and zirconia substrate.
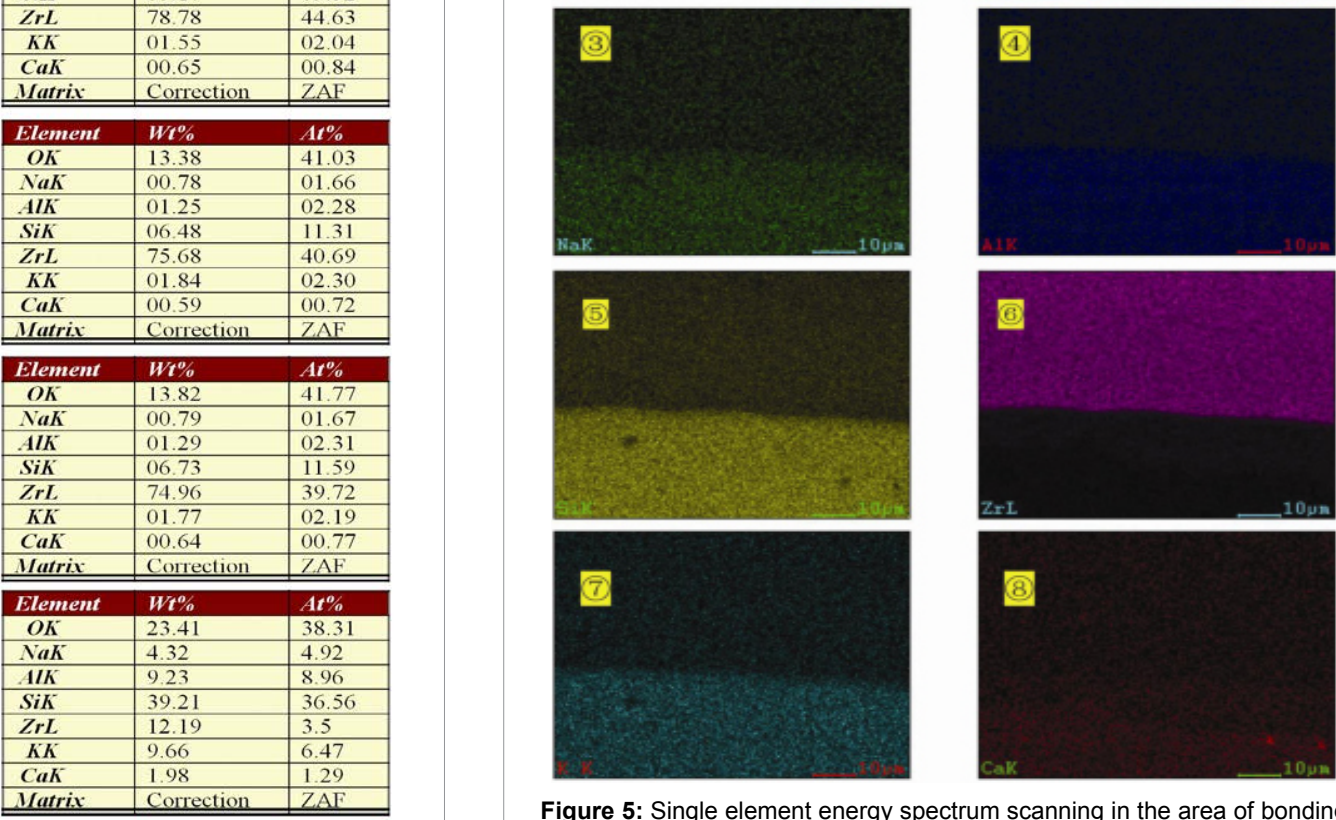

\begin{tabular}{|l|l|l|}
\hline \hline Element & $\boldsymbol{W r} \%$ & $\boldsymbol{A t} \%$ \\
\hline $\boldsymbol{O K} \boldsymbol{K}$ & 25.54 & 39.17 \\
\hline $\boldsymbol{N a K}$ & 05.52 & 05.89 \\
\hline $\boldsymbol{A I K}$ & 09.02 & 08.20 \\
\hline $\boldsymbol{S i K}$ & 43.03 & 37.60 \\
\hline $\boldsymbol{Z} \boldsymbol{r L}$ & 03.89 & 01.05 \\
\hline $\boldsymbol{K} \boldsymbol{K}$ & 09.44 & 05.92 \\
\hline $\boldsymbol{C a K}$ & 03.57 & 02.18 \\
\hline Matrix & Correction & 7.AF \\
\hline \hline
\end{tabular}

Figure 4: Energy spectrum analysis of 5 different areas between zirconia substrate and veneering porcelain.

\begin{tabular}{|c|c|c|c|c|c|}
\hline Element & $\mathbf{A}(\mathbf{w t} \%)$ & $\mathbf{B}(\mathbf{w t} \%)$ & $\mathbf{C}(\mathbf{w t} \%)$ & $\mathbf{D}(\mathbf{w t} \%)$ & $\mathbf{E}(\mathbf{w t} \%)$ \\
\hline OK & 12.31 & 13.38 & 13.82 & 23.41 & 25.54 \\
\hline NaK & 0.72 & 0.78 & 0.79 & 4.32 & 5.52 \\
\hline AlK & 0.82 & 1.25 & 1.29 & 9.23 & 9.02 \\
\hline SiL & 5.17 & 6.48 & 6.73 & 39.21 & 43.03 \\
\hline ZrK & 78.78 & 75.68 & 74.96 & 12.19 & 3.89 \\
\hline KK & 1.55 & 1.84 & 1.77 & 9.66 & 9.44 \\
\hline CaK & 0.65 & 0.59 & 0.64 & 1.98 & 3.57 \\
\hline
\end{tabular}

Table 3: Mass percentage of element content in different areas between the veneering porcelain and zirconia substrate.

\begin{tabular}{|c|c|c|c|c|c|}
\hline Element & $\mathbf{A ~ ( A t \% )}$ & $\mathbf{B}(\mathbf{A t} \%)$ & $\mathbf{C}(\mathbf{A t} \%)$ & $\mathbf{D}(\mathbf{A t} \%)$ & $\mathbf{E}(\mathbf{A t} \%)$ \\
\hline OK & 39.77 & 41.03 & 41.77 & 38.31 & 39.17 \\
\hline NaK & 0.62 & 1.66 & 1.67 & 4.92 & 5.89 \\
\hline AlK & 1.58 & 2.28 & 2.31 & 8.96 & 8.2 \\
\hline SiL & 9.52 & 11.31 & 11.59 & 36.56 & 37.6 \\
\hline ZrK & 44.63 & 40.69 & 39.72 & 3.5 & 1.05 \\
\hline KK & 2.04 & 2.3 & 2.19 & 6.47 & 5.92 \\
\hline CaK & 0.84 & 0.72 & 0.77 & 1.29 & 2.18 \\
\hline
\end{tabular}


the certain element in different areas were listed in Tables 3 and 4, respectively. In addition, the energy-spectrum scanning picture of every single element was illustrated in Figure 5. The element content of $\mathrm{Zr}$ in the outer side of zirconia substrate (Area A) was $78.78 \mathrm{wt} \%$, and was slightly reduced to $74.96 \mathrm{wt} \%$ in the bonding interface (Area C). Besides, $\mathrm{Zr}$ contents were detected to be $12.19 \mathrm{wt} \%$ and $3.89 \%$ in the bonding porcelain layer (Area D) and the veneering porcelain layer (Area E), respectively. The element content of $\mathrm{Si}$ in the veneering porcelain layer (Area E) was $43.03 \%$, and it decreased to be $39.21 \%$ in the bonding porcelain layer (Area D). Besides, small amounts of element $\mathrm{Si}$ were detected both in the bonding interface (Area C) and zirconia substrate (Areas A and B), indicating the diffusion of Si occurred in the zirconia matrix after pre-sintering process. The chemical bonding was confirmed by element diffusion phenomenon, and it was beneficial in the increasing of bonding strength between zirconia and veneering porcelain.

\section{Effect of sintering temperature on the bond strength}

To investigate the effect of sintering temperature on the bond strength, 11 different sintering schedules were performed on 11 groups of specimens. As shown in Table 5, the bond strength was enhanced with the increasing of sintering temperature, and reached to peak value at $960^{\circ} \mathrm{C}$. After then, a declination occurred with the continually increasing of sintering temperature. The p-value between each two groups from Group 3.1 to 3.11 was listed in Table 6.

\begin{tabular}{|c|c|c|c|c|}
\hline $\begin{array}{c}\text { Group No. } \\
(\text { Temperature) }\end{array}$ & $\begin{array}{c}\text { Maximum } \\
(\mathbf{M P a})\end{array}$ & $\begin{array}{c}\text { Minimum } \\
\mathbf{( M P a})\end{array}$ & $\begin{array}{c}\text { Average } \\
\text { (MPa) }\end{array}$ & $\begin{array}{c}\text { Standard } \\
\text { deviation }\end{array}$ \\
\hline $3.1\left(900^{\circ} \mathrm{C}\right)$ & 39.84 & 32.16 & 35.55 & 3.28 \\
\hline $3.2\left(910^{\circ} \mathrm{C}\right)$ & 41.55 & 34.23 & 36.71 & 3.78 \\
\hline $3.3\left(920^{\circ} \mathrm{C}\right)$ & 43.57 & 34.88 & 37.92 & 3.68 \\
\hline $3.4\left(930^{\circ} \mathrm{C}\right)$ & 46.79 & 36.28 & 40.74 & 5.10 \\
\hline $3.5\left(940^{\circ} \mathrm{C}\right)$ & 48.04 & 38.53 & 42.98 & 4.86 \\
\hline $3.6\left(950^{\circ} \mathrm{C}\right)$ & 49.08 & 38.19 & 43.28 & 5.07 \\
\hline $3.7\left(960^{\circ} \mathrm{C}\right)$ & 50.95 & 39.22 & 44.35 & 4.58 \\
\hline $3.8\left(970^{\circ} \mathrm{C}\right)$ & 48.01 & 37.52 & 42.77 & 4.91 \\
\hline $3.9\left(980^{\circ} \mathrm{C}\right)$ & 46.33 & 36.06 & 40.02 & 4.11 \\
\hline $3.10\left(990^{\circ} \mathrm{C}\right)$ & 42.57 & 34.75 & 37.32 & 3.76 \\
\hline $3.11\left(1000^{\circ} \mathrm{C}\right)$ & 39.38 & 32.99 & 35.18 & 3.09 \\
\hline & Value of $\mathrm{F}$ & & $16.88^{*}$ \\
\hline
\end{tabular}

*: significant difference $(p<0.05)$

Table 5: Shear strength of specimen in different sintering temperatures.

\begin{tabular}{|c|c|c|c|c|c|c|c|c|c|c|c|}
\hline $\begin{array}{c}\text { Group } \\
\text { No. }\end{array}$ & 1.1 & 1.2 & 1.3 & 1.4 & 1.5 & 1.6 & 1.7 & 1.8 & 1.9 & 1.10 & 1.11 \\
\hline 1.1 & - & 0.21 & 0.035 & 0.041 & 0.01 & 0.009 & 0.008 & 0.008 & 0.028 & 0.033 & 0.19 \\
\hline 1.2 & $\mathrm{~ns}$ & - & 0.42 & 0.047 & 0.036 & 0.007 & 0.009 & 0.041 & 0.025 & 0.072 & 0.31 \\
\hline 1.3 & $*$ & $\mathrm{~ns}$ & - & 0.034 & 0.029 & 0.011 & 0.015 & 0.036 & 0.027 & 0.46 & 0.035 \\
\hline 1.4 & $*$ & $*$ & $*$ & - & 0.044 & 0.038 & 0.023 & 0.034 & 0.58 & 0.032 & 0.047 \\
\hline 1.5 & $* *$ & $*$ & $*$ & $*$ & - & 0.61 & 0.045 & 0.54 & 0.043 & 0.038 & 0.025 \\
\hline 1.6 & $* *$ & $* *$ & $*$ & $*$ & $\mathrm{~ns}$ & - & 0.039 & 0.73 & 0.049 & 0.008 & 0.009 \\
\hline 1.7 & $* *$ & $* *$ & $*$ & $*$ & $*$ & $*$ & - & 0.041 & 0.044 & 0.01 & 0.013 \\
\hline 1.8 & $* *$ & $*$ & $*$ & $*$ & $\mathrm{~ns}$ & $\mathrm{~ns}$ & $*$ & - & 0.035 & 0.026 & 0.017 \\
\hline 1.9 & $*$ & $*$ & $*$ & $\mathrm{~ns}$ & $*$ & $*$ & $*$ & $*$ & - & 0.042 & 0.039 \\
\hline 1.10 & $*$ & $*$ & $*$ & $*$ & $*$ & $* *$ & $* *$ & $*$ & $*$ & - & 0.046 \\
\hline 1.11 & $*$ & $*$ & $*$ & $*$ & $*$ & $* *$ & $*$ & $*$ & $*$ & $*$ & - \\
\hline
\end{tabular}

ns: no significant difference $(p>0.05)$; *: significant difference $(p<0.05)$; **: very significant difference $(p<0.01)$.

Table 6: p-value between each two groups from Groups 3.1 to 3.11 .

\section{Conclusion}

The average shear strength for specimens with surface morphology of vertical striations, parallel striations, and humps, were measured to be 27.9 MPa, 27.5 MPa, and 37.2 $\mathrm{MPa}$, respectively, demonstrating that humps in the surface of zirconia substrate remarkably enhanced the bond strength between zirconia substrate and veneering porcelain. The pre-sintering process of bonding porcelain was beneficial in improving the bond strength between zirconia and veneering porcelain. A typical triple layer structure of the zirconia layer, pre-sintered bonding porcelain layer, and the veneering porcelain layer was observed by SEM, and an element penetration phenomenon was confirmed by EDS. The result indicated that an element binding force, which was produced in pre-sintering process, made contribution to be increasing of bond strength. Besides, the bond strength could be enhanced with the increasing of sintering temperature, and reached to peak value at $960^{\circ} \mathrm{C}$.

\section{Acknowledgement}

This work was supported by the military clinical key project of advanced technology "Investigation and application of Tooth Defection Fast Simulation Restoration System" (2010gxjs053).

\section{References}

1. Succaria F, Morgano SM (2011) Prescribing a dental ceramic material: Zirconia vs lithium-disilicate. Saudi Dent J 23: 165-166.

2. S Ban (2008) Reliability and properties of core materials for all-ceramic dental restorations. Jpn Dent Sci Rev 44: 3-21.

3. Ho GW, Matinlinna JP (2011) Insights on ceramics as dental materials. Part I: ceramic material types in dentistry. Silicon 3: 109-115.

4. Inokoshi M, Kameyama A, De Munck J, Minakuchi S, Ver Meerbeek B (2013) Durable bonding to mechanically and/or chemically pre-treated dental zirconia. J Dent 41: 170-179.

5. Perdigao J, Fernandes SD, Pinto AM, Oliveira FA (2013) Effect of artificial aging and surface treatment on bond strengths to dental zirconia. Oper Dent 38: 168-176.

6. Sun T, Lai R, Liu R, Shao L (2014) Shear bond strength comparison between conventional dental nano zirconia combinations and new functionally graded nano zirconia combinations after thermal-mechanical cycling. Act Phys Pol A 125: $238-240$

7. Yi YA, Ahn JS, Park YJ, Jun SH, Lee IB, et al. (2015) The effect of sandblasting and different primers on shear bond strength between yttria-tetragonal zirconia polycrystal ceramic and a self-adhesive resin cement. Oper Dent 40: 63-71.

8. Almeida AA Jr, Longhini D, Domingues NB, Santos C, Adabo GL (2013) Effects of extreme cooling methods on mechanical properties and shear bond strength of bilayered porcelain/3Y-TZP specimens. J Dent 41: 356-362.

9. Jang GW, Kim HS, Choe HC, Son MK (2011) Fracture strength and mechanism of dental ceramic crown with zirconia thickness. Procedia Eng 10: 1556-1560.

10. Sailer I, Fehér A, Filser F, Lüthy H, Gauckler LJ, et al. (2006) Prospective clinical study of zirconia posterior fixed partial dentures: 3-year follow-up. Quintessence Int 37: 685-693.

11. Harada K, Shiny A, Yokoyama D, Shinya A (2013) Effect of loading conditions on the fracture toughness of zirconia. J Prosthodont Res 57: 82-87.

12. Sato H, Yamada K, Pezzotti G, Nawa M, Ban S (2008) Mechanical properties of dental zirconia ceramics changed with sandblasting and heat treatment. Dent Mater J 27: 408-414.

13. Guazzato M, Albakry M, Ringer SP, Swain MV (2004) Strength, fracture toughness and microstructure of a selection of all-ceramic materials. Part II. Zirconia-based dental ceramics. Dent Mater 20: 449-456. 